\title{
Cerebral and ocular congenital toxoplasmosis complicated by West syndrome
}

This article was published in the following Dove Press journal:

Clinical Ophthalmology

26 July 2010

Number of times this article has been viewed

\author{
André Omgbwa Eballe' \\ Augustin Ellong ${ }^{2}$ \\ Marie Evodie Akono Zoua ${ }^{2}$ \\ Lucienne Assumpta Bella ${ }^{2}$ \\ Séraphin Ngeufack ${ }^{2}$ \\ Jeanne Mayouego Kouam² \\ Justin Melong ${ }^{3}$ \\ 'Faculty of Medicine and \\ Pharmaceutical Sciences, University \\ of Douala, Cameroon; ${ }^{2}$ Faculty of \\ Medicine and Biomedical Sciences, \\ University of Yaoundé, Cameroon; \\ ${ }^{3}$ Translation Unit, Ministry of Public \\ Health, Yaoundé, Cameroon
}

Correspondence:André Omgbwa Eballe Ophthalmology Unit, Gyneco-Obstetric and Pediatric Hospital of Yaoundé, PO Box 4362, Yaoundé, Cameroon Tel +I I 23799654468

Fax + II 23722212430

Email andyeballe@gmail.com
Abstract: We report a case of a child who presented cerebral and ocular congenital toxoplasmosis associated with West syndrome. He was seen and followed-up in the in patients pediatric and ophthalmologic units at the Gyneco-Obstetric and Pediatric Hospital of Yaoundé in Cameroon between July 2008 and February 2010.

Keywords: toxoplasmosis, West syndrome, Cameroon

\section{Introduction}

Congenital toxoplasmosis is an embryofoetopathy. It has been described all over the world but could be more frequent in the sub-Saharan African regions where traditional practitioners and many cultures do not make mention of the disease and associate some neurological disorders in newborn and children to witchcraft. Most children with congenital toxoplasmosis are developmentally normal ${ }^{1}$ but up to four percent die or have evidence of permanent neurological damage or bilateral visual impairment during the first years of age. ${ }^{2,3}$ It is in this context that West syndrome can develop, and may be defined as a combination of cluster axial spasms and a psychomotor deterioration in an infant with a hypsarythmic aspect, as seen on electroencephalogram (EEG). ${ }^{4}$

We report the case of a child with West syndrome and cerebral and ocular toxoplasmosis, who was seen and followed-up from July 2008 to February 2010 at the ophthalmology unit of the Gyneco-Obstetric and Pediatric Hospital of Yaoundé in Cameroon.

\section{Case report}

In February 2010, a male child aged 25 months was referred to us by a pediatrician for a leucocoria that his parents had observed over three weeks in his right eye. Medical past history of the child revealed that he was born on January, 29th 2008 at 38 weeks of intrauterine life and had a low birth weight $(1.8 \mathrm{kgs})$ with a 10/10 APGAR score at the first minute.

At the age of six months (July 2008), there appeared a psychomotor development retardation with progressive loss of eye-tracking associated with the sudden onset of abnormal movements, characterized by spasm and flexor postures at a rate of about three episodes of 10 spasm and flexor postures per day. The pediatrician made a diagnosis of West syndrome, which was confirmed in August 2008 by an EEG showing hypsarythmia (Figure 1). 


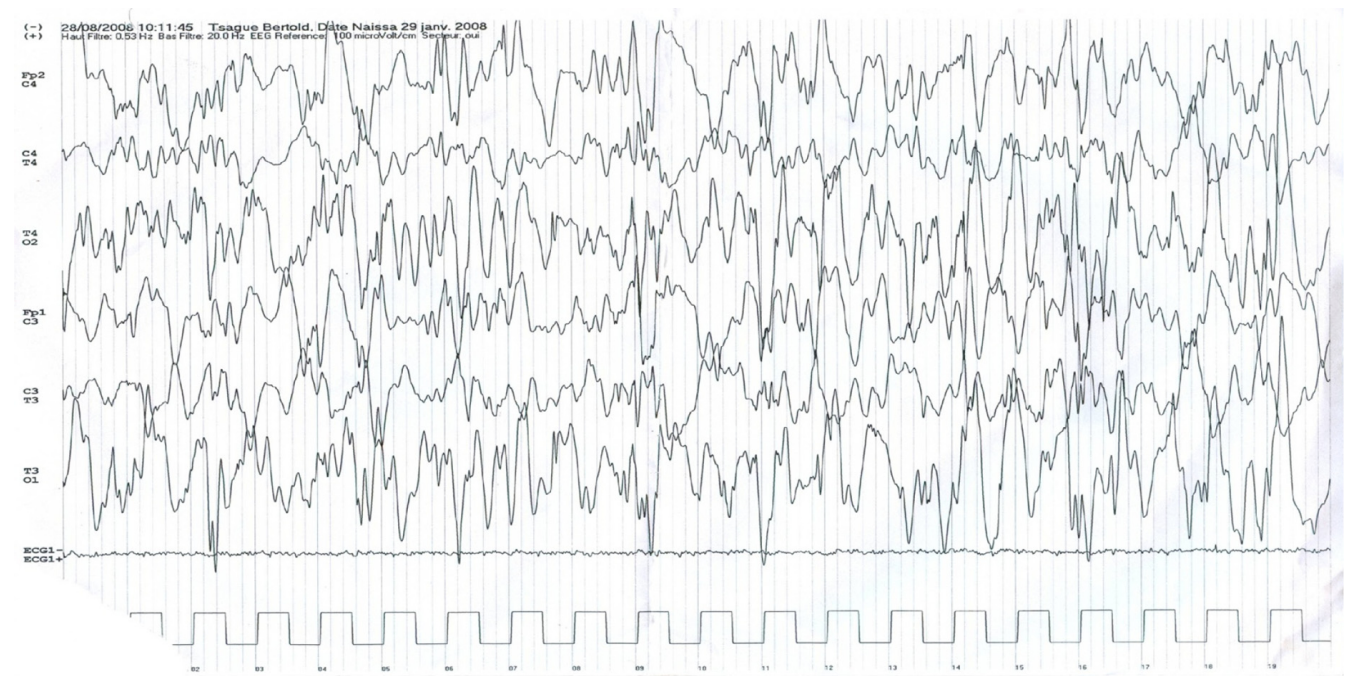

Figure I Electroencephalogram with hypsarythmic tracing.

A cerebral computed tomography (CT) performed reported periventricular and parenchymal calcifications compatible with cerebral toxoplasmosis (Figure 2). The child was placed on general corticosteroid therapy namely prednisolone $1 \mathrm{mg} / \mathrm{kg}$ daily at reducing dosage over 6 months and sodium valproate (Depakine*) for a long duration. At the second and sixth month of treatment, the EEG became normal, and there was a cessation of spasm and flexor postures at 12 months of age.

Ophthalmological examination revealed a total white cataract with a $360^{\circ}$ posterior synechiae in the right eye and a normal anterior segment in the left eye. The ocular fundus in the right eye was inaccessible and we noted in the left eye a large and diffuse pigmented scar of chorioretinitis throughout the temporal retinal quadrant, with vascular sheathing. The intraocular pressure as assessed from digital palpation was normal in both eyes.

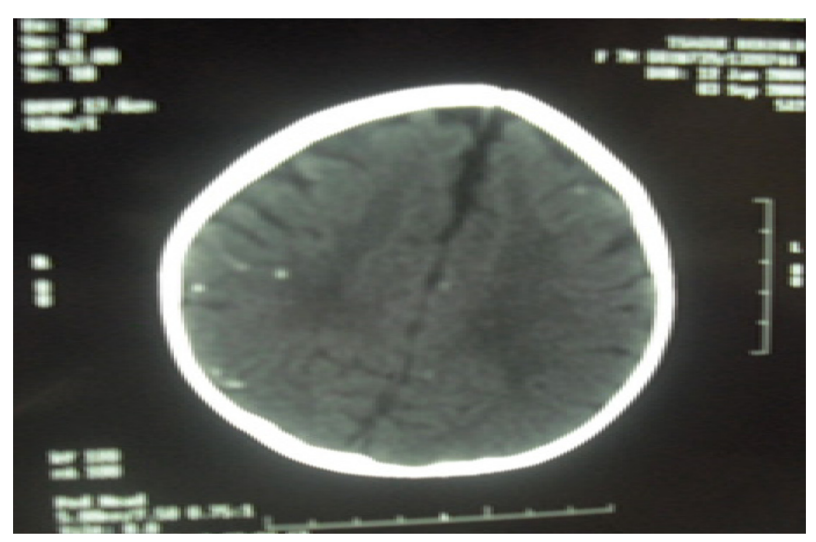

Figure 2 Cerebral CT (75 HU) showing intracerebral calcifications.
Orbital ultrasound showed a posterior vitreous detachment in both eyes, with many intravitreous echoes in the right eye, as a consequence of the vitreous inflammation.

In February 2010, toxoplasmic serologies were performed in the mother and the child using the ELISA techniques in order to detect IgG and IgM directed against Toxoplasma gondii. The maternal serology showed a high concentration of $\operatorname{IgG}(994 \mathrm{IU} / \mathrm{mL})$ with an absence of $\operatorname{IgM}$. In the child, there was also a high concentration of $\operatorname{IgG}$ level $(1102 \mathrm{IU} / \mathrm{mL})$ and an absence of IgM. HIV tests performed in the mother and the child were negative. A serology for the search of congenital rubella was negative. An ENT examination was also performed; no evidence of hearing loss was reported.

Considering these clinical and paraclinical facts, the diagnosis of a cerebral and ocular congenital toxoplasmosis complicated by West syndrome was made. Despite the absence of $\operatorname{IgM}$, the patient was placed on sulfadiazine, $100 \mathrm{mg} / \mathrm{kg} /$ daily, pyrimethamine $1 \mathrm{mg} / \mathrm{kg} /$ daily, and folinic acid $25 \mathrm{mg}$ weekly for six weeks. Cataract, which was secondary to uveitis, was not treated surgically at first contact with the child.

\section{Discussion}

Lesions suggestive of chorioretinitis, the high concentration of $\operatorname{IgG}$ in the mother and the child, and the presence of cerebral calcifications are compatible with a positive diagnosis of toxoplasmosis, which is very likely to be congenital considering neurological and ophthalmological signs during the first months of life. Obviously the presence of congenital 
toxoplasmosis infection is defined by the persistence of specific IgG antibodies beyond 11 months of age; and the absence of congenital infection is defined by undetectable IgG after 2 months of age in the absence of anti-toxoplasma treatment. ${ }^{5}$ This is in line with our clinical case, which at 25 months of age presented with very high concentration of IgG characteristic of toxoplasma gondii.

The absence of maternal antenatal and prenatal toxoplasma serology keeps us from stating with precision the time of maternal contamination, which is very important because it enables us to assess the risk of foetal symptomatic infection, and to take appropriate measures if the risk of contamination is high. Indeed, a French study carried out on 603 pregnancies in 1999 showed that the risk ranges from $61 \%$ at 13 weeks of amenorrhea (WA) to $25 \%$ at $26 \mathrm{WA}$, and $9 \%$ at 36 WA. ${ }^{6}$ Moreover, many French studies have shown a reduction in brain and ocular manifestations of toxoplasmosis infection in children after the mother had received treatment against parasites during pregnancy. ${ }^{7-11}$ On the contrary, some believe that there is no evidence to support this statement. ${ }^{12-14}$

The late discovery of the infection, as is the case in this child is not unusual and might even be a frequent circumstance of discovery. ${ }^{15}$ On an ophthalmologic level, considering the scar nature of ocular lesions in this patient, we can infer that he previously suffered from a panuveitis which certainly might have gone unnoticed; especially as spasm and flexor postures are more alarming for the mother and more noticeable by a pediatrician than a red eye which, on general corticosteroids administered for treating the West syndrome, recovers its whiteness without the intervention of an ophthalmologist. This is the reason why any West syndrome that occurs in sub-Saharan Africa needs multidisciplinary management to find out the cause, especially toxoplasmosis, which is a leading cause of posterior uveitis. ${ }^{16,17}$ This will allow an early eye examination and follow-up, which would spare the child the sequelae of low vision and blindness that ensue and render the disability burdensome, given that West syndrome is a significant cause of psychomotor disability. ${ }^{18}$

The cataract in this case may be a complication of the uveitis, but also probably of the prolonged treatment with corticosteroids. However, it is known that general corticosteroid is most often the cause of bilateral cataract. It was not treated surgically at the first contact with the child considering the inflammatory nature that would have occurred after surgery. Furthermore, a favorable visual prognosis is not guaranteed in these cases, as the cataract is only a single element in an ocean of ocular lesions of poor functional prognosis; but surgery could only be done later after it has been ascertained that the uveal inflammation resolutely ended since more than six months ago in order to minimize the possibility of an inflammation re-occurrence and see whether a minimum useful visual acuity can be restored in the child. This surgical act will possibly enable an ophtalmoscopic report of the right eye retina if the vitreous has a minimum transparency.

West syndrome may be idiopathic, that is to say, without any apparent cause, and is said to be symptomatic when there are identifiable brain lesions as is the case with our patient. It appears this form is more disabling than an idiopathic or isolated West syndrome. ${ }^{18}$

The diagnosis of West syndrome is made clinically by the existence of spasm and flexor postures of sudden onset between the age of 3 to 7 months, and by EEG presenting generally disorganized and irregular traces, while the cerebral CT and MRI detect the cerebral lesion, which is the cause of the disease. It is the diagnostic methodology of this syndrome, ${ }^{13}$ and this is what was done in the pediatric unit of our hospital. Given the results of the different examinations conducted, the West syndrome in this child would therefore be a neurological manifestation of a cerebral congenital toxoplasmosis.

Congenital rubella is a differential diagnosis of congenital toxoplasmosis. It is a cause of significant congenital malformations realizing the Gregg's tripod namely: ocular lesions (cataract), cardiac lesions (persistent arterial duct, pulmonary stenosis), and ENT manifestations characterized by sensorineural deafness. ${ }^{19}$ According to some authors, "salt and pepper" chorioretinitis, involving the periphery and the posterior pole of the retina is more frequently found in congenital rubella, but its real impact so far remains unknown because in most cases, cataract obstructs the ophthalmoscopic examination of the retina. ${ }^{20}$ In this case report, there was no biological element to confirm this etiology, especially as the rubella serology was negative.

Given the severity of neuropsychological and sensory lesions of congenital toxoplasmosis, primary prevention through awareness raising and education of women of childbearing age on how to prevent congenital toxoplasmosis is necessary. The removal of cats, proper cooking of meat, of hands hygiene and drinking water hygiene should be encouraged in our context of developing countries. ${ }^{21}$ This primary prevention will probably have a real effect on the reduction of congenital infections. 


\section{Conclusion}

A multidisciplinary follow-up of the child is required, especially as the deepness of the neurological and sensory deficits caused by the disease is not yet totally revealed. A comprehensive neuropsychological examination by a neuropediatrician is necessary to accurately assess the child's growth and his cognitive capacities, before elaborating a suitable treatment strategy. The presence of West syndrome should cause the search for toxoplasmosis until the contrary is proven in our context where the state-of-the-art science is gradually being adopted thereby putting in perspective many traditional African beliefs. Primary prevention of toxoplasmosis in the community should be encouraged.

\section{Limitations}

We were not able to provide the ocular fundus photography due to lack of adequate equipment to obtain them.

\section{Disclosure}

No conflicts of interest were declared in relation to this paper.

\section{References}

1. Salt A, Freeman K, Prusa A, et al. Determinants of response to a parent questionnaire about development and behaviour in 3 year olds: European multicentre study of congenital toxoplasmosis. BMC Pediatr. 2005;5:21.

2. Guerina NG, Hsu HW, Meissner HC, et al. Neonatal serologic screening and early treatment for congenital Toxoplasma gondii infection. The New England Regional Toxoplasma Working Group. $N$ Engl J Med. 1994;330:1858-1863.

3. Gras L, Wallon M, Pollak A, et al. Association between prenatal treatment and clinical manifestations of congenital toxoplasmosis in infancy: A cohort study in 13 European centres. Acta Paediatrica. 2005;94: 1721-1731.

4. Roger J, Bureau M, Dravet CH, Genton P, Tassinari CA, Wolf P. Les syndromes épileptiques de l'enfant (3eme édition) Herts, UK. John Libbey and Co Ltd publishers. 2002:47-64.

5. Lebech M, Joynson DH, Seitz HM, et al. Classification system and case definitions of Toxoplasma gondii infection in immunocompetent pregnant women and their congenitally infected offspring. European Research Network on Congenital Toxoplasmosis. Eur J Clin Microbiol Infect Dis. 1996;15:799-805.
6. Dunn D, Wallon M, Peyron F, Petersen E, Peckham C, Gilbert R. Mother-to-child transmission of toxoplasmosis: Risk estimates for clinical counseling. Lancet. 1999;353:1829-1833.

7. Douche C, Benabdesselam A, Mokhtari F, Le Mer Y. Value of prevention of congenital toxoplasmosis. J Fr Ophtalmol. 1996;19:330-334.

8. Knerer B, Hayde M, Gratz G, Bernaschek G, Strobl W, Pollak A. Direct detection of Toxoplasma gondii with polymerase chain reaction in diagnosis of fetal toxoplasma infection. Wien Klin Wochenschr. 1995;107:137-140.

9. Excler JL, Piens MA, Maisonneuve H, Pujol E, Garin JP. Dépistage de la toxoplasmose acquise chez la femme enceinte et de la toxoplasmose congénitale chez le nouveau-né. Lyon Med. 1985;253:33-38.

10. Desmonts G, Couvreur J. Toxoplasmose congénitale. Ann de Pediatr (Paris). 1984;31:805-809.

11. Roux C, Desmonts G, Mulliez N, et al. Toxoplasmosis and pregnancy. Evaluation of 2 years of prevention of congenital toxoplasmosis in the maternity ward of Hôpital Saint-Antoine (1973-1974). J Gynecol Obstet Biol Reprod (Paris). 1976;5:249-264.

12. Desmonts G, Couvreur J. Congenital toxoplasmosis. N Engl J Med. 1974;290:1110-1116.

13. Thoumsin H, Senterre J, Lambotte R. Twenty-two years of screening for toxoplasmosis in pregnancy: Liege-Belgium. Scand J Infect Dis. 1992;84 Suppl:84-85.

14. Wallon M, Peyron F, Lebech M, Petersen E, Gilbert R, Dunn D. Prenatal treatment and the risk of congenital toxoplasmosis: preliminary findings from two cohort studies [abstract No 94.] European Society for Research in Pediatrics annual meeting, Szedeg, Hungary 1997. Pediatr Res. 1997;42:400.

15. Wirden M, Botterel F, Romand S, Ithier G, Bourée P. Intérêt du dépistage en post-partum de la toxoplasmose congénitale après primo-infection maternelle en fin de grossesse. J de Gynécologie Obstétrique et Biologie de la Reproduction octobre. 1999;6(28):566.

16. Dollfus H, Dureau P. Congenital toxoplasma chorioretinitis transmitted by preconceptionally immune women. Br J Ophthalmol. 1998;82:1444-1445.

17. Ronday MJ, Stilma JS, Barbe RF, et al. Aetiology of uveitis in Sierra Leone, West Africa. Br J Ophthalmol. 1996;80:956-961.

18. Le syndrome de West. Encyclopédie Orphanet Grand Public. 2008. Available from: http:\\www.orpha.net/data/patho/Pub/fr/ West-FRfrPub894v01.pdf. Accessed Jun 16.

19. François Aubert, Philippe Guittard. Essentiel Médical de poche $2^{\mathrm{e}}$ édition; Universités Francophones. Paris, France: Ellipses Aupelf/Uref Publisher. 1995:448-451.

20. Jack J Kanski. Clinical ophthalmology, a systematic approach, 6th ed. Oxford, UK. Butterworth Heinemann Elsevier Publisher. 2007:482.

21. Bowie WR, King AS, Werker DH, et al. Outbreak of toxoplasmosis associated with municipal drinking water. Lancet. 1997;350:173-177.
Clinical Ophthalmology

\section{Publish your work in this journal}

Clinical Ophthalmology is an international, peer-reviewed journal covering all subspecialties within ophthalmology. Key topics include: Optometry; Visual science; Pharmacology and drug therapy in eye diseases; Basic Sciences; Primary and Secondary eye care; Patient Safety and Quality of Care Improvements. This journal is indexed on Submit your manuscript here: http://www.dovepress.com/clinical-ophthalmology-journal

\section{Dovepress}

PubMed Central and CAS, and is the official journal of The Society of Clinical Ophthalmology (SCO). The manuscript management system is completely online and includes a very quick and fair peer-review system, which is all easy to use. Visit http://www.dovepress.com/ testimonials.php to read real quotes from published authors. 